\title{
“DESANISTIA" E DISPUTA PELOS SENTIDOS DA ANISTIA POLÍTICA DE MILITARES
}

\author{
“DISAMNESTY” AND THE DISPUTE OF WORD MEANING IN THE POLITICAL AMNESTY \\ OF THE MILITARY
}

\section{David Barbosa de Oliveira}

Doutor em Direito pela UFPE. Professor adjunto da UFC. Professor colaborador do Mestrado e doutorado em Sociologia da UECE e permanente do Doutorado em Políticas Públicas.

E-mail: dvdbarol@gmail.com

Recebido em: 09/08/2019

Aprovado em: 25/06/2020

RESUMO: Este artigo almeja perceber as representações sobre anistia, assim como as disputas de poder e de sentido dos que militam na questão. Objetivamos com ele trazer a lume o tratamento diferenciado recebido pelos militares anistiados do Ministério da Defesa. O Ministério da Defesa interpreta que os militares anistiados devem submeter-se a um regime jurídico específico e finda por suprimir direitos destes. Assim, utilizando a análise de discurso e a pesquisa documental, buscamos expor como é construído, dentro do Estado, esse discurso, e a existência de uma distinção que suprime direitos, a dignidade dos anistiados e, por que não dizer, o próprio sentido da anistia.

Palavras-chave: Militar. Supressão de direitos. Anistia.

ABSTRACT: This article aims to perceive the representations about amnesty, as well as the disputes of power and word meaning of those who are engaged in this issue. We aim to bring to light the differential treatment received by the military who were granted amnesty by the Brazilian Ministry of Defense. The Ministry of Defense interprets that the military who were granted amnesty must submit to a specific legal regime and ends by suppressing their rights. Thus, using discourse analysis and archival research, we seek to show how this discourse is constructed within the State, and the existence of a distinction that suppresses rights, the dignity of the amnestied, and, why not admit, the very meaning of amnesty.

Keywords: Military. Suppression of rights. Amnesty.

SUMÁRIO: Introdução. 1 Anistia, justiça de transição e direitos humanos. 2 Análise de Discurso Crítica. 3 A "desanistia": a representação do tratamento diferenciado conferido pelo Ministério da Defesa aos militares anistiados. 4 Mudança social e anistia: a disputa do anistiado pela anistia e seu sentido. Considerações finais. Referências. 


\section{INTRODUÇÃO}

Este texto descende de outras pesquisas que tratam da disputa pelo sentido da anistia militar dentro e fora do Estado. Metodologicamente, a pesquisa está apoiada na análise de discurso, pelo viés da Análise de Discurso Crítica (ADC) de Norman Fairclough (2001, 2003, 2010), possibilitando pôr em destaque o direcionamento ideológico dos textos, bem como a assimetria de poder entre discursos jurídicos.

O corpus da pesquisa se consubstancia em processos jurídicos, pareceres ministeriais e 15 entrevistas com a sociedade civil organizada sobre a anistia militar. Seguindo a codificação de transcrição proposta por Magalhães (2000), com algumas adaptações, os entrevistados foram identificados com um codinome, tomado aleatoriamente, sem qualquer referência ao seu nome ou metáfora que representasse o grupo ou sua identidade e o entrevistador/pesquisador foi identificado com seu próprio nome: Iniciais do nome do autor (D.O.). Importa ainda dizer que palavras pronunciadas de forma enfática, em tom forte, indicando ênfase, foram postas em caixa alta, que barras inclinadas representam interrupções no fluxo da fala e que três pontos entre parênteses significam que parte do texto foi omitida.

Importa também deixar evidente que a disputa discursiva sobre a anistia impede que esse problema possa ser analisado desprezando o enunciado contrário, sendo então necessário que todos os discursos que lutam pelo seu sentido e por sua hegemonia sejam postos no centro do debate. Assim, cabe dizer que não trilhamos, neste artigo, o tradicional caminho de, com amparo na "natureza" jurídica do instituto, explicar seu alcance e aplicação, que é uma estratégia monofônica do Direito, utilizada para fins dogmáticos. O escopo foi, dialogicamente, o caminho inverso, ou seja, observar os discursos sobre a anistia política, mostrando suas disputas e contradições na construção dos sentidos da anistia.

Desse modo, destacamos, neste artigo, a parte do corpus referente às entrevistas realizadas com os militares que foram anistiados, bem como com militares que reproduzem o pensamento dominante nas Forças Armadas, que chamamos de estabelecidos (ELIAS e SCOTSON, 2000), e possuem uma visão mais restrita da anistia. As entrevistas foram transcritas e os nomes dos entrevistados foram alterados a fim de evitar suas identificações.

Cada grupo destacado possui um discurso que, em decorrência da posição de onde fala e de acordo com a identidade que assume, representará os fatos de modo diverso, havendo, decorrente disso, disputas pela determinação do sentido da anistia e de suas representações. Objetivamos, então, reproduzir trechos que denotam as representações a respeito do sentido da anistia política, almejando perceber se existem representações sociais diferentes. Como resultado, encontramos, além de significados díspares em cada grupo sobre a anistia e suas representações, tensões dialógicas e disputas de poder nessas representações, que geram reflexos desses discursos dentro dos órgãos estatais. Por fim, registramos que, na análise, seguiremos os passos propostos por Fairclough (2009), mas não adotaremos categorias específicas de análise linguística.

\section{ANISTIA, JUSTIÇA DE TRANSIÇÃO E DIREITOS HUMANOS}

A anistia é assunto que carrega contradições e intensas disputas por seu sentido. As contradições decorrem, em parte, da má compreensão do instituto. Em 10 de dezembro de 2014, por exemplo, o jornal O Globo (2015) exibiu a manchete Comissão da Verdade pede revogação parcial da Lei da Anistia e responsabiliza ex-presidentes. Meses antes, militares reunidos no Rio de Janeiro lançaram Carta Aberta à Presidente da República, denunciando os tratamentos discriminatórios a eles pelo Ministério da Defesa, exigindo o cumprimento da Lei de Anistia. A carta dos militares anistiados divulgada em 23 de junho de 2014, entre os festejos da Copa do Mundo de futebol, buscava chamar a atenção da sociedade para o problema dos militares anistiados 
políticos ${ }^{1}$. Mas como podemos explicar o aparente paradoxo de vermos movimentos sociais que militam em um mesmo campo social e possuem interesses convergentes pedirem, a um só tempo, a revogação e o cumprimento da Lei de Anistia? A resposta consiste no fato de se tratarem de duas anistias distintas que estão presentes no mesmo texto legal.

A Lei de Anistia de 1979, que inaugura o último ciclo anistiador brasileiro, estende-se até os dias atuais e possui tanto normas que versam sobre a extinção de punibilidade dos tipos políticos e comuns cometidos no período, quanto normas de reparação dos anistiados. Assim, quando se requer que a Lei de Anistia seja revogada ou tida como não válida - como se deu com a Arguição de Descumprimento de Preceito Fundamental $n^{\circ} 153$ e com o caso Gomes Lund versus Brasil na Corte Interamericana de Direitos Humanos - relaciona-se à parte penal da Lei de Anistia de 1979. Entretanto, quando se afirma que a Lei de 1979 e os demais instrumentos anistiadores devem ser cumpridos, refere-se à parte reparadora da anistia, que pode ser encontrada, além de em outras comissões, nos requerimentos junto à Comissão de Anistia do Ministério da Justiça. Esse falso paradoxo mostra a atualidade do problema, assim como o desconhecimento de grande parte da população sobre a questão.

É certo dizer que a anistia também lida de perto com as questões dos direitos humanos. Ainda que não haja normatização internacional sobre os limites e a legitimidade das leis de anistia, inúmeros julgados da Corte Interamericana de Direitos Humanos tratam do assunto, impondo critérios de legitimidade e limites formais para a aceitação das leis, rechaçando as anistias que servem tão somente para proteger, sob a impunidade, agressores dos direitos humanos, como demonstram o Caso Barrios Altos, Gomes Lund e Almonacid Arellano.

É importante dizer também que o presente artigo tem o objetivo de abordar a anistia dentro do quadro teórico da Justiça de Transição. Essa justiça, segundo Kai Ambos (2009), compreende os mecanismos e processos da sociedade para enfrentar um legado autoritário de abusos do passado em grande escala, assegurando responsabilidade, justiça e reconciliação, abrangendo a justiça realizada durante a transição de regimes (ditadura para democracia, como in casu), assim como em processos de paz dentro de um conflito em curso. Na Justiça de Transição, a anistia é apenas um dos instrumentos para realizar a transição entre regimes, devendo ser somada a outros que instrumentalizem reparações, investigações, políticas de memória, entre outros. Nessa justiça, que se ocupa de mecanismos e processos para enfrentamento de legados autoritários em grande escala, a anistia é apenas um dos instrumentos para realizar a transição entre regimes, devendo ser somada a outros que instrumentalizem reparações, investigações, políticas de memória. Nesse contexto, deve-se afastar a anistia absoluta ditada pela tradicional e histórica ideia de esquecimento dos fatos e priorizar as anistias condicionadas, haja vista não eximirem automaticamente de punição os atos cometidos.

Além disso, queremos aclarar que os direitos humanos aqui são vistos em sua verve crítica. Assim, como Rubio, entendemos que "los derechos humanos poseen un carácter ambivalente, tienen un potencial emancipador pero éste está construido sobre un suelo o un piso estructural de desigualdades y de asimetrías que se desenvuelven entre diferentes grupos sociales" (2015, p. 186). Em outros termos, podemos dizer que a luta pelos direitos humanos gestados pela ordem burguesa se desenvolveu e se consolidou sobre uma divisão social, econômica, política, cultural, geográfica e epistêmica, que impossibilitou, por dinâmicas de dominação, que a sociedade pudesse existir viabilizando condições dignas em todas as suas dimensões. Ainda com apoio em Rubio, é irrefutável a afirmação de que "el sistema sobre el que se basa la organización moderna y capitalista no permite que las luchas que lo cuestionan puedan comunicar e irradiar desde sus particularidades, un horizonte de universalidad conflictivo, más diverso, más abierto y plural" (2015, p. 186). Assim, aqui utilizamos a discussão dos direitos humanos não como um ponto de saída, mas, antes, como um espaço em disputa, como um ponto a chegar.

${ }^{1}$ Documento disponibilizado por José Bezerra da Silva, advogado e militar anistiado que participou do protesto. Revista de Direito Brasileira | Florianópolis, SC | v. 28 | n. 11 | p.164-182 | Jan./Abr. 2021 
Esclarecemos, por fim, com essas observações, que os direitos humanos, tal como aponta Flores, "mais que direitos 'propriamente ditos', são processos; ou seja, o resultado sempre provisório das lutas que os seres humanos colocam em prática para ter acesso aos bens necessários para a vida" (2009, p. 28). Assim, os direitos humanos não devem confundir-se com os direitos positivados no âmbito nacional ou internacional, pois uma constituição ou um tratado internacional não criam direitos humanos. Para Flores (2009, p. 28), "o problema não é de como um direito se transforma em direito humano, mas sim como um 'direito humano' consegue se transformar em direito".

Entendemos que este estudo findou por demostrar esse caráter procedimental e tensional dos direitos humanos. Os Direitos humanos, como afirma Douzinas, "representam a necessária e impossível reivindicação de lei e de justiça" (2009, p. 383). Os direitos humanos introduzem uma tensão nos direitos positivados decorrente das lutas sociais que lhes antecedem. É o caráter utópico desses direitos, e não o normativo, que lhes possibilita fazer a crítica e resistir às ações que impedem o pleno desenvolvimento humano. Assim, com Flores, os direitos humanos são o resultado sempre provisório da luta social pela dignidade (2009, p. 31). Desse modo, podemos agora continuar entendendo que apontaremos qual foi/é a anistia possível e como se dá essa disputa.

\section{ANÁLISE DE DISCURSO CRÍTICA}

Em regra, inicialmente, nos anos 1970, mesmo reconhecendo o papel da linguagem na estruturação das relações de poder na sociedade, grande parte das teorias, segundo Wodak (2004, p. 228), "focalizava os aspectos formais da linguagem que constituíam a competência linguística dos falantes, e que podiam, em teoria, ser isolados dos exemplos reais do uso da linguagem". Até na Pragmática, em que se observa a relação entre linguagem e contexto, dava-se pouca atenção às questões de hierarquia social e poder. Assim, como esclarece Van Dijk (1999, p. 23), "el ADC puede entenderse como una reacción contra los paradigmas formales (a menudo 'asociales' $o$ 'acriticos') dominantes en los años sesenta y setenta”.

Efetivamente, a ADC vem preencher uma lacuna teórica e metodológica situada entre as teorias linguísticas formais e as teorias sociais. A ADC, como uma rede de estudiosos, emergiu depois de um pequeno simpósio em Amsterdã, em janeiro de 1991. A tentativa de firmar a disciplina fez vertentes acadêmicas se aproximarem; contudo, essa é uma unificação difícil de ser alcançada em razão de sua base teórica plural e das mais diversas formações dos pesquisadores. $\mathrm{O}$ que a ADC "teoriza é em particular a mediação entre o social e o linguístico" (CHOULIARAKI e FAIRCLOUGH, 1999, p. 16.), por meio de instrumentos teóricos e metodológicos. Portanto, essa proposta de análise tem como propósito o debate teórico e metodológico do discurso, ou seja, a linguagem como prática social.

Tem como princípios a ADC, segundo Van Dijk (1999): o discurso trata de problemas sociais; as relações de poder são discursivas; o discurso constitui a sociedade e a cultura; o discurso faz um trabalho ideológico; o discurso é histórico; o enlace entre o texto e a sociedade é mediado; a análise de discurso é interpretativa e explicativa; e o discurso é uma forma de ação social (1999, pp. 24 e 25). Assim, discurso aqui será tratado como prática social e não como algo estático, estanque. Isso implica perceber o discurso como um modo de ação e um modo de representação, historicamente situados, que, ao mesmo tempo em que é constituído socialmente, é constitutivo de identidades sociais, representações sociais, gêneros discursivos (FAIRCLOUGH, 2001).

Na ADC de Fairclough (2001), o discurso tem três dimensões: o texto, a prática social e a prática discursiva. A prática social traz diversos elementos junto com o texto e é da análise da relação dialética entre eles que podemos perceber as relações de poder. O discurso é, também, uma dimensão da prática social, um modo de ação sobre o mundo e a sociedade, um elemento da vida social ligado a outros elementos (MAGALHÃES, 2004). Por fim, baseado em Foucault, Fairclough (2001) também utiliza o conceito de prática discursiva, que compreende os processos de produção, 
distribuição e consumo de texto, que são processos sociais relacionados a ambientes econômicos, políticos e institucionais particulares. Em um enquadramento teórico mais recente, no entanto, de acordo com Resende e Ramalho "a centralidade do discurso como foco dominante passou a ser questionada e o discurso passou a ser visto como uma dimensão das práticas sociais” (2013, p. 29). Assim, Fairclough não abandona essa primeira apresentação tridimensional de sua teoria, mas fortalece a análise da prática social, constituída pelo discurso, ou semiose, a atividade material, as relações sociais e o fenômeno mental (FAIRCLOUGH, 2003).

As práticas, de acordo com Chouliaraki e Fairclough (1999), são os modos de agir habituais, em tempos e espaços específicos, pelas quais as pessoas conjuntamente investem recursos materiais ou simbólicos, conectando estruturas abstratas (como a linguagem) aos mecanismos e eventos concretos (julgamento jurídico). A análise das estruturas é feita em articulação às ordens do discurso, aos elementos que reproduzem o discurso, ao passo que a análise da ação envolve gêneros discursivos, elementos que transformam o discurso. A prática relacionase, então, tanto com a estrutura quanto com a ação, sendo ambígua a maneira pela qual essa palavra é utilizada por Fairclough (2003), podendo, então, ser observada tanto por meio da ação social, quanto pela estrutura social. Essa ambiguidade possibilita a intermediação da prática às estruturas e aos eventos, conforme explica o Realismo Crítico.

No Realismo Crítico, as relações entre práticas são de um equilíbrio provisório, jamais acabado, inerente a qualquer sistema aberto. Por conseguinte, a ADC, pautada no Realismo Crítico, defende uma visão da vida, do social e, como consequência, do discurso como um sistema aberto. Mecanismos gerativos de estratos diversos (físico, biológico, social) operam simultaneamente com seus poderes causais, produzindo efeitos imprevisíveis nos outros domínios. Assim, segundo Resende (2008), estruturas emergem de ações anteriores e ações atuais são constrangidas por estruturas criadas por outras ações. Isso quer dizer que estruturas são resultados de ações sociais, assim como ações sociais decorrem de estruturas. Com efeito, a ação social é percebida como dependente e constrangida por permanências relativas (estruturas) que constantemente se reproduzem, mas que também se transformam parcialmente, a depender do equilíbrio das circunstâncias sociais (CHOULIARAKI e FAIRCLOUGH, 1999). Assim, para Fairclough, "os agentes sociais não são agentes 'livres', eles são constrangidos, mas não têm suas ações totalmente determinadas" (2003, p. 22). A ADC de Fairclough, portanto, fica situada entre a estrutura e a ação.

A operação de qualquer mecanismo que possui certo poder sobre esses estratos é sempre mediada pela operação simultânea de outros, de forma tal que não se reduzem a uma sobredeterminação (ALTHUSSER, 1979), mas sempre interiorizam aspectos dessas influências. Segundo Chouliaraki e Fairclough, "o objeto de estudo nas ciências sociais é a vida social e o principal assunto, particularmente na ciência social crítica, é a relação entre as esferas da vida e a atividade social, o econômico, o político e o cultural" (1999, p. 20). É possível, portanto, identificar modos nos quais outras dimensões da sociedade estão enraizadas e emergem, por exemplo, do Direito (e sendo por ele determinado), contudo sem se reduzir a ele. Assim, ao contrário de teorias que percebem o fenômeno jurídico como uma esfera social autoconstituinte e autorreferente, recebendo apenas perturbações de outros sistemas sociais, na ADC, os textos e discursos jurídicos estão em diálogo direto com textos da Economia, da Política, da Educação, da Ciência (entre outros) e com diversos discursos, possibilitando estudos sobre essas trocas (MAGALHÂES, MARTINS, RESENDE, 2017).

Assim, uma prática particular, como o anistiamento político, envolve configurações de diferentes elementos da vida social. Esses elementos são chamados de dimensões da prática e cada momento é visto como interiorizando os outros sem ser redutível a eles. Assim, na anistia, no Brasil, os discursos e os pareceres da Comissão de Anistia dialogam com os do Ministério da Defesa, do Supremo Tribunal Federal e da Corte Interamericana de Direitos Humanos, estando nas práticas dos conselheiros da Comissão e dos anistiados, sobredeterminando os eventos, as práticas, 
os textos e os discursos da Comissão, fomentando uma reprodução ou transformação de suas posições, ideologias, crenças, mas não os determinando.

Uma prática particular traz ainda consigo diferentes elementos da vida: tipos particulares de atividade localizados espaçotemporalmente; pessoas particulares e suas experiências, com conhecimentos e disposições em relações sociais particulares; recursos semióticos e modos de usar a língua. Esses diversos elementos da vida trazidos em conjunto, dentro de uma prática específica, são chamados dimensões da prática. Para Chouliaraki e Fairclough (1999), cada dimensão de uma prática é sobredeterminada também por outras dimensões suas sem se reduzir a elas, permanecendo a prática constantemente aberta a mudanças, podendo cada prática, simultaneamente, ser articulada com seus elementos e junto com muitas outras de múltiplas posições sociais e com diversos efeitos sociais.

Segundo Fairclough (2008), diferente da abordagem de Foucault, que favorece mais a reprodução das ações, a ADC possibilita uma análise, por meio de estruturas e de ações, permitindo examinar as mudanças sociais. A análise das práticas sociais de anistia permite, portanto, perceber não apenas os efeitos sobre eventos (enunciação do voto na Comissão de Anistia, no Supremo Tribunal Federal e na Corte Interamericana de Direitos Humanos), mas também sobre a conjuntura desses eventos (conjuntos relativamente estáveis de anistiados, conselheiros, advogados gerais da união, ministros juízes, materiais, tecnologias e práticas de restrição ou ampliação de direitos dos anistiados) relacionados, na sustentação ou na transformação de estruturas jurídicas.

Os textos, na ADC, conforme expõe Magalhães, "produzem efeitos sobre as pessoas, e tais efeitos são determinados pela relação dialética entre texto e contexto social" (2004, p. 114). Com essa opção teórica, Fairclough (2003) admite que, no texto, podemos encontrar elementos de outras dimensões das práticas sociais, inclusive elementos discursivos do poder. Além disso, também se está constituindo uma teoria em que o discurso é determinado pelo social, ao mesmo tempo em que, dialeticamente, pode reproduzir ou transformar o social. Fairclough, com esse recorte teórico, opta pela compreensão de que o discurso/a linguagem repercute sobre a realidade, afastando-se, por exemplo, da postura de Rorty (1994), em que o discurso refere-se sempre a outro discurso da realidade e não à realidade em si. Assim, na ADC, os textos têm efeitos sobre as pessoas, as ações, as relações sociais e o mundo material. Os textos produzem efeitos sobre as práticas sociais e vice-versa.

A relação entre a linguagem e a sociedade é um fato na ADC. É, então, uma abordagem que tem por base a percepção de que a linguagem é uma parte irredutível da vida social dialeticamente interconectada a outros elementos sociais. A palavra, em si, é desprovida de poder, mas encarna, em verdade, a força dos indivíduos na sociedade, sendo uma forma a ser preenchida pelas relações de poder. Daí Bourdieu assinalar que compreender "lingüísticamente el poder de las manifestaciones lingüísticas, buscar en el lenguaje el principio de la lógica y de la eficacia del lenguaje institucional, es olvidar que la autoridad sobreviene al lenguaje desde fuera" (2008, p. 87). No mesmo sentido, ratifica Wodak, ao acentuar que, "a linguagem não é poderosa em si mesma - ela adquire poder pelo uso que os agentes que detêm o poder fazem dela" $(2004$, p. 236). No máximo, para Bourdieu (2008), a linguagem se limita a representar a autoridade, manifestando-a, simbolizando-a, pois a fala oficial do porta-voz tem os mesmos limites que a instituição que a delegou. $\mathrm{O}$ autorizado a falar só pode atuar por meio das palavras porque sua palavra concentra $\mathrm{o}$ capital simbólico acumulado pelo grupo de cujo poder está investido. Assim, o significado linguístico é inseparável das relações sociais, do poder e da ideologia.

Segundo Resende e Ramalho, a ADC é um modelo teórico e metodológico "aberto ao tratamento de diversas práticas da vida social, capaz de mapear relações entre os recursos linguísticos utilizados por atores sociais e grupos de atores sociais e aspectos de rede de práticas em que a interação discursiva se insere" (2013, pp. 11 e 12). Desse modo, é a ADC um precioso instrumento para o estudo dos processos ideológicos que medeiam relações de poder e controle por meio da linguagem. 


\section{A "DESANISTIA": A REPRESENTAÇÃO DO TRATAMENTO DIFERENCIADO CONFERIDO PELO MINISTÉRIO DA DEFESA AOS MILITARES ANISTIADOS}

Na perspectiva de Minayo (2009), as representações são definidas como categorias do pensamento que expressam a realidade, explicam-na, justificando-a ou questionando-a. Essas percepções são consideradas consensualmente importantes, permanecendo na história as mais diversas correntes do pensamento social. O termo surge com Durkheim e permanece nas problematizações sociológicas, como apontam as atuais reflexões de Becker (2009) sobre as "representações da sociedade".

É certo que a representação não consegue dar conta da realidade "em si", de toda a sua complexidade, sendo sempre uma tentativa de aproximação, de abarcar a totalidade, limitando-se a certos aspectos da experiência existencial, frequentemente contraditórios, nos quais os agentes sociais disputam espaço e poder na lida diária. Segundo Minayo (2013), As representações não são necessariamente conscientes e, mesmo depois de elaboradas por algum teórico, elas são a mistura das ideias das elites, das massas, da filosofia corrente e das contradições vividas no plano das relações socais de produção, estando, por isso mesmo, nelas, tanto elementos de dominação quanto de resistência.

É preciso deixar claro, contudo, que o termo representação aqui não se apoia em uma suposta essência, um conteúdo imutável; pelo contrário, as representações são percebidas aqui como algo instável, constrangidas pelas lutas de representações, pelas suas contingências. As representações são disputadas socialmente e transformam-se histórica e contextualmente, de modo que não há essências nas representações sociais. As representações são constituídas em meio a embates e disputas sobre a realidade, manifestando tensões, hierarquias, disputas sociais. Conforme aponta Rajagopalan, aqui a linguagem "é um palco de lutas sobre representação, isto é, sobre quem tem o direito de representar o mundo e de que forma" (2003, p. 32), confluindo para uma política de representação. Assim, a despeito de algumas críticas que o termo representação pode receber, sua aplicação deve ser entendida não como um número, mas como um fenômeno disputado dentro de uma política de representações.

A ADC de Fairclough (2003) utiliza-se da representação dessa maneira, percebendo o discurso como um modo de representar aspectos particulares do mundo, como o processo, as relações e as estruturas do mundo material, as ideias, os sentimentos e as crenças. Aspectos particulares do mundo podem ser representados de maneira diferente, o que implica a existência de vários discursos, de diversas relações com o mundo e com as demais pessoas, de visões e posições sociais diferentes no mundo. Os discursos não apenas representam o mundo como ele é, ou como deveria ser, eles também são projetivos, alinhados a projetos de mudança de mundo em direções específicas. Um discurso pode ensejar inúmeras representações, não havendo relação direta entre um tipo de discurso e uma espécie de representação.

Aqui, nos deteremos nas representações dos anistiados ao tratamento distinto deferido pelo Ministério da Defesa aos militares. Desse modo, buscaremos dar visibilidade às representações dos anistiados no discurso do Ministério da Defesa, que se baseia nos pareceres da AGU (Parecer $n^{\circ} 59$ de 2007 da CONJUR/MD, Portaria Normativa $n^{\circ}$ 657/MD, de 2004 e, especificamente, a Portaria $n^{\circ}$ 209-DGP, de 2005). A representação dessa distinção realizada pelo Ministério da Defesa pode ser percebida nas falas dos militares anistiados, ao afirmarem, por exemplo, que "em 1964, saiu a minha reforma ex officio. (...) E aí, começou a minha luta. Naquele tempo, eu tinha 30 pra 31. Hoje eu tô com 80 e continuo, né? Por quê? Porque eles estão nos desanistiando". ${ }^{2}$

O termo "desanistia" possui um sentido singular, referindo-se, aqui, ao tratamento dado aos militares anistiados pelas Forças Armadas. Tanto produtores quanto intérpretes estão diante de

${ }^{2}$ Capitão Alberto.

Revista de Direito Brasileira | Florianópolis, SC | v. 28 | n. 11 | p.164-182 | Jan./Abr. 2021 
escolhas sobre como usar a palavra e o modo de expressar significado por meio dela. Daí, mesmo ante a possibilidade de ser individual ou socialmente contestado, o sentido de "desanistia" é particularmente importante nesta seção, pois surge nas falas dos militares anistiados políticos, não no sentido de se retirar a validade da anistia, como se estes pudessem ser novamente presos ou processados pelos fatos antes típicos, ou serem suspensas as reparações econômicas concedidas, mas no sentido de serem distinguidos, quanto ao gozo de direitos, dos seus pares da caserna.

A criação desse regime diferenciado para os militares anistiados foi, segundo o anistiado Carlos, um modo que os militares estabelecidos criaram para retirar os anistiados do militarismo. Para ele, ser anistiado é estar dentro do militarismo, ser compreendido dentro do Estatuto dos Militares, ter direitos iguais aos militares estabelecidos. Para o Capitão Dimas, a criação da distinção entre militares anistiados "é uma outra punição". Não basta que tenham sido expulsos da caserna e impedidos de criar uma carreira, as Forças Armadas impedem agora o exercício de seus direitos. Ainda para ele, apesar de os militares de hoje não serem os mesmos do golpe, eles são formados para a reprodução da ideologia estabelecida, daí ele concluir: "a mentalidade dominante no meio militar, puniu ou está punindo até a morte. E agora, estão punindo a família”. A criação da diferenciação entre os militares é uma forma de continuar a punição iniciada em 1964, só que agora, além do anistiado, pune-se toda a família, haja vista a repercussão sobre os direitos dos dependentes dos militares advindos do novo regime do anistiado.

Para o Capitão Dimas, o que se impõe, por parte das Forças Armadas, "é morrer punindo, eles têm a pior má vontade com essa lei 10.559, porque eles queriam aplicar a lei até a metade como eles vinham aplicando". "Aplicar a lei até a metade", é não aplicar, por exemplo, o artigo 13 em sua integralidade. Esse artigo dispõe que "no caso de falecimento do anistiado político, o direito à reparação econômica transfere-se aos seus dependentes, observados os critérios fixados nos regimes jurídicos dos servidores civis e militares da União”. Para o Capitão Dimas,

[...] eles só leem até a virgula, não leem depois da vírgula. (...) Porque se lessem depois da virgula, estaríamos todos no regime jurídico militar, então não teríamos mais porque brigar, continua, agora estamos brigando por família. A família tem que provar que é dependente, e que não tem renda senão não pagam a pensão.

Os termos sublinhados, para o Capitão Dimas, são critérios que igualam os militares anistiados aos demais, impondo tratamento isonômico dentro do mesmo regime jurídico. Se o artigo 13 afirma que "o direito à reparação econômica transfere-se aos seus dependentes, observados os critérios fixados nos regimes jurídicos dos servidores civis e militares da União", então o anistiado deve incorporar o direito à reparação como se fosse um militar como outro qualquer, em todos os critérios de seu regime jurídico, afastando a possiblidade de criação de regime diverso, pois devem ser "observados os critérios fixados nos regimes jurídicos dos servidores civis e militares da União”. Na prática, essa distinção prorroga o direito dos dependentes dos anistiados, como acentua o Capitão Dimas:

[...] agora estamos brigando por família. A família tem que provar que é dependente, e que não tem renda senão não pagam a pensão (...) O milico que está na ativa, morre, todo milico tem uma folha, um arquivo na unidade que pertence, tem lá um fichário, uma pasta com a vida militar. Tem lá, beneficiários, beneficiários quem são: a mulher ou quem passou a dependente e filhas. Filhas! Assim é o estatuto militar do regime de pensões depois que a lei, 3765 assim prevê. Então o militar da ativa que morre, não tem nenhum problema, vai alguém e pega, beneficiárias. Para nós vamos lá, anistiados, nomeia um sindicante, um oficial sindicante, pra ver quem de fato vivia as despesas, quer dizer, quem era dependente econômico. E isso ai poderia ser feito como o pessoal da seção de ativos, é uma coisa que poderia ser feito dia 2 , ou em uma semana, um mês. Chega a anos para receber isso ai. 
Assim, para os anistiados, o tratamento é diverso, tendo-se que, dentro do processo de habilitação, fazer prova de que o dependente do anistiado de fato possuía uma situação de dependência econômica, conforme estabelece o artigo 29, da Portaria $n^{\circ}$ 209-DGP, devendo o comandante da OM/OP diligenciar no sentido de comprová-la. Com a aplicação dos critérios fixados nos regimes jurídicos dos servidores militares da União, não se sustentaria a diferença introduzida entre os dependentes da reparação permanente e continuada ${ }^{3}$ e os dependentes de pensão militar ${ }^{4}$, uma vez que seriam aplicados os mesmos critérios dos militares estatuídos, não havendo que existir habilitação dos dependentes dos militares anistiados.

Em sua luta por mudança social, os anistiados também se posicionam quanto ao argumento de não poderem perceber a pensão em razão de não terem eles contribuído com o desconto de 1,5 por cento sobre o seu soldo. Defende o Capitão Dimas o argumento de que o artigo $9^{\circ}$, da Lei 10.559, veda essa possiblidade, ao estabelecer que os valores pagos por anistia não poderão ser objeto de contribuição ao INSS, a caixas de assistência ou fundos de pensão ou previdência, nem objeto de ressarcimento por estes de suas responsabilidades estatutárias. Ora, o Regimento Militar impõe descontar 1,5\% para que os dependentes tenham acesso à pensão, mas não se pôde realizar o desconto do anistiado inicialmente, porque ele foi forçadamente posto para fora da caserna e, depois, porque a Lei veda expressamente. Assinala o Capitão Dimas que "muitos de nós quisemos descontar e não conseguimos". Como descontar se um ato de força do regime de exceção ou a vedação legal, que busca beneficiá-lo, o impede de fazê-lo? Para os anistiados, não é justo alijar o direito em razão da impossibilidade de cumprir o dever imposto. Eles defendem, assim, que é desarrazoado e paradoxal negar direito ao anistiado, pensão aos seus dependentes, por exemplo, se a legislação, com o escopo de lhe favorecer, impede qualquer desconto sobre a sua reparação.

Também é destacado pelos militares, na busca por afastar a desigualdade de tratamento que lhes é imposta pelo artigo 16, da Lei 10.559, que foram um pouco silenciados ou superestimados no parecer da CONJUR/MD. Esse artigo, em verdade, é entendido pelos anistiados como a pedra angular da Lei 10.559, possibilitando uma ampliação dos direitos dos anistiados, advogando no sentido contrário à interpretação do Ministério da Defesa. Pela interpretação da Consultoria desse Ministério, com base no artigo 16, da Lei 10.559/02, é vedada a percepção de mais de um benefício pelo anistiado, como a acumulação de pensão militar e reparação de anistia, alegando que seria enriquecimento sem causa à custa do erário da União. Alega a CONJUR/MD que a Lei está apenas resguardando outros direitos ou benefícios concedidos pela legislação anterior.

Contudo, não é isso que entendem os militares anistiados. Para eles, parece ser mais razoável uma interpretação que amplie os direitos dos anistiados, haja vista que o escopo dos artigos $8^{\circ}$ e $9^{\circ}$ dos Atos das Disposições Constitucionais Transitórias foi reparar pessoas que, por motivação exclusivamente política, foram, de acordo com o artigo $2^{\circ}$, da Lei 10.559/02, atingidos por atos institucionais ou complementares, ou de exceção, na plena abrangência do termo ou punidos. ${ }^{5}$ Ora, se a legislação busca reparar o que o Estado de exceção fez, não parece razoável vedar a acumulação de benefícios que vão ao encontro de reduzir as diferenças entre os anistiados e quem permaneceu na caserna.

Para os anistiados, o escopo do ato anistiante é tentar reposicionar, na medida do possível, o indivíduo, na situação em que se encontrava, antes dos atos de exceção; contudo, como isso é impossível, então, busca-se tratar a pessoa de modo diverso, a fim de minorar as diferenças com

\footnotetext{
${ }^{3}$ Dependentes de militares anistiados que percebiam indenização.

${ }^{4}$ Dependentes de militares que não saíram das Forças Armadas.

${ }^{5}$ Punidos com transferência para localidade diversa daquela onde exerciam suas atividades profissionais; com perda de comissões já incorporadas ao contrato de trabalho; impedidos de exercer, na vida civil, atividade profissional específica em decorrência das portarias reservadas do Ministério da Aeronáutica.
} 
quem permaneceu na carreira. A Legislação de anistia é voltada, em sua parte reparadora, para um tratamento diferenciado, auferindo vantagens, a quem sofreu violações aos seus direitos por motivação exclusivamente política. Daí, o artigo 16 aduzir que os direitos expressos na Lei 10.559 não excluem os conferidos por outras normas legais ou constitucionais, sendo vedada a acumulação de quaisquer pagamentos, benefícios ou indenização com o mesmo fundamento, facultando-se, contudo, a opção mais favorável. É límpida, para eles, a intenção de favorecer o anistiado, vedando, apenas e tão-somente, a acumulação de pagamentos ou benefícios ou indenização com o mesmo fundamento.

Ora, a pensão referida no Estatuto Militar e a reparação constante na Lei 10.559 não ascendem do mesmo fundamento, posto que, como explicita ao artigo $2^{\circ}$, da Lei 10.559 de 2002, a reparação econômica decorre da declaração de anistiado político em razão de motivação exclusivamente política, quando atingidos por atos institucionais ou complementares, ou de exceção na plena abrangência do termo, punição ou outro motivo expresso na Lei, ao passo que a pensão decorre de opção realizada pelo militar de desconto sobre o soldo. Como possuem fundamentos distintos, a legislação não veda a sua acumulação. Daí, o Capitão Dimas dizer:

[...] então se nós não estamos descontando, por uma determinação legal, eles alegam que nós queremos duas vantagens, recebemos a indenização mais a pensão, o que é uma mentira, não existe nenhum documento nosso, nem na justiça, que nós queremos a pensão militar, nós queremos é a aplicação da pensão militar conforme as normas militares no Brasil, o... Como é que chama? O estatuto militar e a lei de pensão, nós queremos é a aplicação.

O que os militares anistiados almejam é a aplicação da legislação vigorante, de modo a serem reconhecidos como militares, gozando todos os direitos do Estatuto Militar, assim como perceberem as reparações indenizatórias em razão das perseguições por motivos exclusivamente políticos que sofreram, sendo também reconhecidos como anistiados. Desse modo, os anistiados buscam a reintegração ao regime do qual são oriundos e a efetivação mais ampla possível da anistia e de seus direitos.

Essa “desanistiação” também se dá na impossibilidade prática de progressão dos militares aos postos mais altos da carreira Daí o anistiado Coronel Bruno afirmar que "a lei ficou melhor para o torturador do que para os legalistas”. Para ele, todos os golpistas, inclusive os torturadores, "puderam seguir a sua carreira militar natural, eles estão no Estado Maior, alguns chegaram ao generalato, outros interromperam como coronéis. Mas no caso nosso, nós fomos impedidos de fazer uma carreira". Os anistiados tiveram sua carreira interrompida, ficando muitos anos fora das Forças Armadas, sendo inclusive esse o argumento, dentro da Constituinte de 1987, para não os readmitir ou os pôr direto na reserva. Esse fato é percebido pelos anistiados como mais uma forma de diferenciar e estigmatizar o grupo de militares que foi posto para fora das Forças Armadas por suas convicções político-ideológicas. Nesse sentido, o Coronel Bruno, arremata, dizendo:

[...] recentemente, você pode verificar que o Vinícius de Moraes foi promovido a primeiro ministro, o último estágio da carreira que também é uma carreira de escolha, teoricamente, é uma carreira de escolha, não é? Ele foi promovido e você verifica que nós militares, que não éramos generais, paramos no posto de coronel. (...) Então, há uma perseguição contínua ainda, que é específica com os militares cassados.

Para ele, inserir os anistiados no Estatuto dos Militares e dar todas as progressões que lhe são de direito é muito importante politicamente (dentro e fora do seio militar), posto que poria em pé de igualdade anistiados e estabelecidos, e daria uma mensagem muito clara aos últimos: os valores democráticos devem ser defendidos, não sendo admissível qualquer tratamento 
desvantajoso a quem defendeu a democracia. Assim, a luta pelo acesso dos militares anistiados às patentes discricionárias das Forças Armadas (generalato, por exemplo) deve ser o reconhecimento de que a luta pelo Estado de Direito deve ser difundida e assegurada, de que os valores democráticos e a Constituição devem ser sempre defendidos. O Coronel Bruno reforça a contradição da não progressão ao oficialato, afirmando que, no caso de Prestes, por exemplo, ele deveria "ser anistiado como marechal, né? Não é general porque todos os subordinados dele foram marechais". Deve-se então desfazer o que está em curso, no Brasil, com a "perseguição" aos anistiados e a valorização de quem derrubou um governo democraticamente eleito. Todos os golpistas puderam seguir a sua carreira militar natural, chegando alguns ao oficialato, mas, no caso dos anistiados, vedou-se forçadamente de se fazer essa mesma carreira, impedindo que todos pudessem alcançar as patentes mais altas.

Há, portanto, por parte dos anistiados, uma busca para serem reconhecidos como militares estatutários, afastando o regime diferenciado do anistiado político, assim como militar anistiado. Esse regime, criado pelo Ministério da Defesa, segundo o Capitão Dimas, "é para aqueles que, estudantes, dona de boteco, que perderam o que tinham, pessoas indenizadas, e não estavam ligados a nenhum setor, não eram metalúrgicos, não eram petroleiros, não eram funcionário público e não eram militar". Contudo, essa distinção promovida, pelo Ministério da Defesa, entre os militares anistiados e os demais, também repercute, logicamente, na autoimagem dos militares cassados. A denegação desses direitos influencia a imagem que o indivíduo faz de si, prejudicando sua autoestima. As representações explicitadas pelos anistiados, como estando "marcados" como subversivos - "o anistiado é uma segunda categoria", faz "parte de um gueto", preso político era comunista e "comunista é um bicho desprezível" - relatam claramente como eles imaginam que a sociedade os representa.

A pecha de comunista, preso político, anistiado, ainda hoje rende preconceito, trazendo consigo forte conotação negativa. Há, para os anistiados, um continuum de ordem decrescente entre os termos "comunista", "subversivo", "preso político" e "anistiado político", trazendo sempre uma conotação negativa, como nota o Capitão Dimas: "esse bicho desprezível, nós ainda somos olhados hoje. Então houve uma época em que havia em certas repartições militares inclusive um setor especial para tratar o anistiado".

Assim, as relações jurídicas geram a consciência de poder se respeitar, haja vista que, ao respeitar os demais, consegue, ao mesmo tempo, o respeito de todos os outros. Contudo, a denegação de direitos destrói a possibilidade desse autorrespeito, à medida que inflige ao sujeito o sentimento de não possuir o status de igualdade. Nesse sentido, a criação, pelo Ministério da Defesa, do regime diferenciado para os militares anistiados políticos suprime a possibilidade de autorrespeito, posto que as pessoas sujeitas a uma mesma circunstância são tratadas de maneira diversa. Desse modo, o Parecer $n^{\circ} 59$, da CONJUR/MD, é contra o estatuto da igualdade, que deveria ser assegurado pela legislação, criando, ou melhor, perpetuando uma distinção iniciada em 1964.

\section{MUDANÇA SOCIAL E ANISTIA: A DISPUTA DO ANISTIADO PELA ANISTIA E SEU SENTIDO}

Os obstáculos que surgem ao longo das atividades dos anistiados podem ser molas propulsoras da mudança social, ao converter indignação e sentimentos negativos (vergonha, ira) em estratégias para superação dos obstáculos. Tais sentimentos podem realizar um deslocamento da atenção dos atores para a própria ação, para o contexto em que ela ocorre e para as expectativas ali em causa, sendo o impulso motivacional para a luta por mudança social. Assim, impulsos para o conflito ou para alteração do contexto social, em um ambiente político e cultural propício para tanto, pode favorecer mudanças nas estruturas sociais (MAGALHÃES, 2017). 
A mudança social necessita que se opere, na sociedade, não mais a reprodução da diferença, pois precisa de práticas sociais que abracem o diferente. Para Fairclough, "a prática social não apenas reflete a realidade que é independente desta; ela é também uma ativa implicadora nas mudanças da realidade" (2001, p. 31). A prática da diferença realizada pelo Ministério da Defesa pode ser transformada, possibilitando o reconhecimento dos militares anistiados. Essa possibilidade de mudança e superação dos obstáculos da prática do Ministério da Defesa, para Fairclough (1999), é explicada em virtude de a sociedade e de o discurso serem sistemas abertos, com ações não totalmente previsíveis, havendo amplo campo de possibilidades restringidas e fomentadas pelas estruturas sociais.

As estruturas sociais, a um só tempo, constrangem a ação para sua reprodução e fornecem recursos para sua transformação. As práticas, como o tratamento desigual aos militares anistiados pelo Ministério da Defesa, possuem apenas estabilidade relativa, posto que estão em disputa e transformação, não se podendo falar de estabilidade hegemônica. As estruturas definem um potencial, existindo contingências que bloqueiam ou estimulam determinadas práticas. Esse diálogo entre práticas fornece elementos para a reprodução ou a transformação das outras práticas, daí podermos afirmar que o tratamento desigual entre os militares instrumentaliza discursos para a mudança social.

Com efeito, a distinção imposta entre os militares é a razão de os movimentos sociais e dos próprios anistiados buscarem estratégias para alteração das práticas sociais e dos discursos que restringem seus direitos e prejudicam sua identidade. A disputa pelo sentido, pela "natureza" jurídica da anistia que se desenhou no debate legislativo da Lei 6.683/79, e nos textos constitucionais, que passou pela definição doutrinária dos limites do instituto, pelos julgamentos das cortes nacionais e internacionais, pelas representações dos movimentos sociais a favor e contra a ampliação dos direitos dos militares anistiados políticos, é a luta pela mudança social referente aos direitos dos anistiados.

A intenção de mudança social dos militares anistiados não se encerra nas práticas da Comissão de Anistia ou nas práticas e pareceres do Ministério da Defesa, pois eles "ganham" o mundo social. Assim como o parecer conclusivo da Comissão de Anistia procura outros a fim de se realizar no mundo, implicando respostas e resistências, os pareceres do Ministério da Defesa também criam ações pragmáticas, possibilitando respostas por meio de outros enunciados. Assim como o parecer da Comissão é rediscutido no Ministério da Defesa, essa prática do Ministério da Defesa produz também um enunciado que possibilita falas de outros sujeitos, impulsionando para outros sentidos; pois o/a ouvinte, ao perceber e compreender o significado do enunciado emitido pelo falante, desempenha, além da função passiva, uma função ativa, responsiva. Daí, na busca de ser reconhecido com os direitos dos militares não cassados e com as reparações dos anistiados, cria estratégias para alterar o sentido dos textos que restringem seus direitos. Assim, por meio do Judiciário, atua a fim de superar os obstáculos à plena realização de sua condição de anistiado, alterando as estruturas sociais que o/a limitam.

Assim, ações são ajuizadas, na Justiça Federal, para reverter a repercussão da exclusão dos anistiados do Estatuto Militar, por exemplo, sobre a pensão de suas filhas. De início, urge ressaltar que nem todas as ações prosperam, devendo as filhas de militares anistiados enquadraremse nos requisitos legais. ${ }^{6}$ Supridas essas condições, a pensão às filhas de militares, como um todo, depende da data da morte do de cujos, de acordo com o entendimento do Supremo Tribunal Federal (BRASIL, Mandado de Segurança: 20032 DF). Assim, com base na lei vigente na época do óbito do militar, se morreu antes da Medida Provisória (MP) $n^{\circ} 2.131 / 00$, faz jus à pensão, pois não

\footnotetext{
${ }^{6}$ Desse modo, não prosperam as ações em que as filhas de militares anistiados não suprem as exigências legais de ser solteira e depender economicamente do de cujus ou quando sob sua dependência econômica, sob o mesmo teto, e expressamente declarada, na organização militar competente, a filha, a enteada e a tutelada, nas condições de viúvas, separadas judicialmente ou divorciadas, desde que não recebam remuneração, conforme exige o artigo 50 do Estatuto dos Militares (BRASIL, Processo n⿳0 0042830-89.2012.4.02.5101, p. 541).
} 
havia, até então, a necessidade de optar se contribuiria ou não com 1,5\% do soldo. Porém, se a morte se deu depois dessa data, o direito da filha dependerá de ter o militar optado ou não pela contribuição de 1,5\%. As filhas dos militares anistiados acompanham o entendimento dos demais militares, regendo a querela em razão da data do óbito do anistiado (BRASIL, Processo $\mathrm{n}^{\circ}$ 2009.51.01.023644-3 e Processo $\mathrm{n}^{\mathrm{o}}$ 0019265-33.2011.4.02.5101). Se o óbito é anterior à MP, possui direito; se depois, não.

Entretanto, há decisões que avançam e ampliam os direitos dos militares anistiados. Assim, há deferimento de pensões, mesmo com óbito posterior a 28 de dezembro de 2000, data da MP. Nesses casos, ante a negativa da pretensão administrativa da pensão, em razão do claro entendimento obstativo do Ministério da Defesa, recorre-se ao judiciário, que tem entendido que, "a despeito de não haver contribuição, o direito à percepção de pensão pelos dependentes foi mantido, o que se depreende da inteligência dos artigos 13 e 16, da Lei 10.559 de 2002" (BRASIL, Processo $n^{\circ}$ 0041343-02.2010.4.02.5151). O artigo 31, da MP $n^{\circ}$ 2.131/2000, assim como da MP $n^{\circ}$ 2.215-10/2001, que estabelece prazo peremptório para a opção ao benefício de pensão militar previsto na Lei $n^{\circ} 3.765 / 60$, para o juízo, não apresenta qualquer relevância ao caso em questão: seja por que o citado limite temporal, findado em 31 de agosto de 2001, aplica-se tão-somente à hipótese de eventual manifestação de vontade do militar em renunciar à mencionada vantagem, de modo que àquele que, à época da edição da indigitada Medida Provisória, ostentasse a qualidade de militar, estaria assegurada a manutenção dos benefícios previstos na Lei $n^{\circ} 3.765 / 60$, mediante o desembolso de contribuições no importe de 1,5\% a título de pensão militar, salvo se, dentro do prazo previsto, renunciasse expressamente a tal direito; seja porque

[...] considerando o fato de que o demandante foi excluído das fileiras da Aeronáutica em 1970, somente vindo a ser declarado anistiado no ano de 2004, não mostra-se, no mínimo razoável, que fosse compelido a se pronunciar sobre o seu possível interesse à manutenção do citado benefício até o último dia de agosto de 2001, período em que não mais integrava à Força Armada por força do ato político de exceção, até mesmo porque tal vantagem seria mantida de forma automática no caso de silêncio do militar, conforme exegese do art. 31, da mencionada Medida Provisória (BRASIL, Processo $\mathrm{n}^{\circ}$ 004134302.2010.4.02.5151).

Desse modo, o Judiciário avança na questão e se direciona ideologicamente no sentido oposto ao do Ministério da Defesa, entendendo que o militar posto fora da caserna ficou impedido de contribuir e que, se dentro estivesse, seu silêncio seria entendido como aceitação da cobrança, não sendo razoável que suas filhas quedem impedidas de ter acesso ao benefício.

Quanto à não promoção dos anistiados ao oficialato, também há a interposição de ações, nos tribunais superiores, buscando modificar essa denegação de direitos. O Supremo Tribunal Federal possuía o entendimento de que, para se efetivar essas promoções, bastaria o cumprimento dos requisitos formais, ou seja, prazos de permanência e, por consequência, a idade-limite, na forma dos Regulamentos e Estatuto dos Militares, até o posto máximo da carreira. Assim, possibilitava-se o direito ao anistiado político militar de ser promovido também por merecimento, por não poder submeter-se aos critérios subjetivos e competitivos dos militares que permaneceram em atividade (BRASIL. Recurso Extraordinário nº 165.438-4 DF).

Esse direcionamento ideológico, entretanto, foi alterado, em 2007, passando a entender a Suprema Corte que o instituto da anistia política, previsto no art. $8^{\circ}$ do ADCT, deve ser interpretado de forma ampliativa, possibilitando ao beneficiário o acesso às promoções, como se na ativa estivesse, contudo obstando àquelas que dependeriam, por lei, de aprovação em concurso público ou aproveitamento em cursos (BRASIL, Recurso Extraordinário $n^{\circ}$ 174.161 EDv-ED/DF). Consequentemente, o militar anistiado tem direito a todas as promoções como se na ativa estivesse; porém, tal benefício é restrito às promoções da carreira a que pertencia o militar. Assim, por 
exemplo, o praça anistiado não tem direito a ser promovido ao oficialato, por ser de carreira diversa, visto que a carreira de praça se encerra na graduação de Suboficial. Nesse sentido, também passou a entender o Superior Tribunal de Justiça ao decidir que "o militar anistiado tem direito a todas as promoções a que faria jus se na ativa estivesse considerando a situação dos paradigmas" (BRASIL, Recurso Especial no 1357700/RJ). Assim, se, dentre os oficiais, o paradigma alcançou o oficialato, o anistiado também pode, observando apenas critérios objetivos, ser a ele equiparado. ${ }^{7}$ Assim, não há mais espaço para promoções puramente formais que alcançasse o anistiado e o recolocasse em local da carreira acima de onde poderia chegar. Por certo que esse entendimento reparava de modo especial o militar anistiado, compensando com essa ação as inúmeras perdas nos anos durante os quais esteve cassado. $\mathrm{O}$ entendimento mais recente das mais altas cortes do País retrocede, restringindo os direitos dos anistiados militares.

Ainda dentro da problemática da promoção de anistiados ao oficialato, a promoção de Lamarca pela Comissão de Anistia produziu repercussões também no ambiente judicial, que necessitam de algumas explicações. O parecer conclusivo de Lamarca declarou que ele, Oficial de Infantaria, caso continuasse no serviço ativo, também alcançaria o posto de Coronel e seria transferido para a reserva remunerada ex officio, ao atingir a idade-limite de cinquenta e nove anos, em 27 de outubro de 1996, conforme preceitua o artigo 98, I, alínea a, da Lei nº 6.680, de 9 de dezembro de 1980, Estatuto dos Militares. Conforme o artigo 50 desse estatuto, considerando que contaria com mais de 30 anos de serviço ao ser transferido para a inatividade, passaria à reserva remunerada com a percepção de remuneração correspondente ao grau hierárquico superior, ou seja, com a remuneração do posto de General de Brigada.

Argumentam os militares estabelecidos, que comungam do mesmo discurso do Ministério da Defesa e dos clubes militares, que a concessão dessas progressões fere a hierarquia e a disciplina, pedras angulares das Forças Armadas, pondo em risco a própria estrutura castrense. Em verdade, muito mais coisa está em jogo nessa reparação e progressão de Lamarca. Para o grupo de militares que enaltecem o golpe de 1964, Lamarca não tem direito algum, pois traiu as Forças Armadas. Desse modo, quando indagado, o General Flávio, do grupo que não saiu da caserna, sobre esse movimento de revisão dos fatos, e da reintegração de militares anistiados, feito pela Comissão de Anistia, afirma:

G. F.: (...) pra mim acabou, mas ninguém quer acabar. Esse negócio do Lamarca, não é isso? É isso?

D. O.: Não é qualquer militar, na verdade o Lamarca é um dos militares ...

G. F.: Não, o Lamarca é um TRAIDOR, Lamarca é um desertor. Então ele não tem direito a NADA.

Argumenta esse grupo que essas reintegrações de militares que estavam fora das Forças Armadas, como a de Lamarca, quebram a hierarquia e a disciplina, fundamentos da estrutura militar. Essa posição, ante as leis de anistia, foi bastante comum durante as discussões parlamentares dessas leis, sendo, ainda hoje, uma tônica preponderante nesse grupo. Nesse sentido, comenta o Coronel Hélio, que faz parte dos militares entrevistados que apoiam o golpe:

Ora, se o Lamarca, que foi o maior inimigo das forças armadas da época, do governo militar, foi anistiado. Agora recebe, a família recebe a patente de Coronel que era [inaudível] porque era Capitão na época. Eu também era capitão naquela época. Então ele poderia ter sido Coronel, então, deram o posto de Coronel. Agora

\footnotetext{
${ }^{7}$ Há outros caminhos de promoção dos anistiados ao oficialato. O mandado de segurança 11.249 - DF confirmou a promoção ao Generalato de Bolivar Marinho. O impetrante havia sido promovido ao generalato pela Portaria $\mathrm{n}^{\circ} 1.179$, de 21 de junho de 2005, do ministro da Justiça, que o promoveu na inatividade ao posto de general de brigada; contudo, a Portaria $n^{\circ} 1.555$, de 3 de agosto de 2005, do mesmo ministro, anulou a Portaria 1.179, mantendo várias vantagens, mas retirando a promoção ao generalato. $\mathrm{O}$ writ foi favorável ao impetrante, devolvendo a patente antes concedida e decidindo definitivamente a questão (BRASIL, Mandado de Segurança no 11249/DF).
} 
queriam que ele fosse a General com direitos... Aí não dá, pô. Ele já foi muito beneficiado, era o maior inimigo do exército, na época. Isso é só pra enfeitar o pavão. O maior inimigo do exército, na época, era: Lamarca, aquele Marighella e aquela Guerrilha do Araguaia. Os três foram inimigos do próprio país.

Vê-se que não é só uma questão de cumprir a legalidade, mas de não "enfeitar o pavão", de não remexer a história oficial que agora está em disputa pelos novos donos do poder, é uma questão de afastar a luz sobre os vencidos, perpetuando a visão dos vencedores, reafirmando a ótica, sem qualquer contraditório e pluralidade, de que Lamarca, Marighella e a guerrilha do Araguaia continuam sendo perigos ao Brasil. Atende também a essa questão a pecha de revanchistas dada por esse mesmo grupo aos que querem ver os torturadores processados e presos pelo Estado de Direito de 1988. É claro que, junto com o sentido de Anistia, há uma memória e uma história em disputa pelos dois grupos que lutam historicamente pela hegemonia do poder. É óbvio que, ao rever os fatos da ditadura, o intuito é trazer à tona posições reprimidas e falas caladas pelo estado de exceção; delimita-se por essa revisão um novo lugar ideológico, a busca por uma nova hegemonia. Esses militares comungam do mesmo discurso dos clubes militares e do Ministério da Defesa, daí esses agentes buscarem opções à decisão da Comissão de Anistia.

De fato, o Clube Naval, o Clube Militar e o Clube de Aeronáutica, que representam, respectivamente, oficiais da Marinha, do Exército e da Aeronáutica, resistem à declaração da Comissão, afirmando que Lamarca desertou e que promoções post mortem, nessas situações, ferem o Decreto $\mathrm{n}^{\mathrm{o}} 3.998$, de 5 de outubro de $2001 .^{8}$ Esse descontentamento com a concessão de anistia pela Comissão a Lamarca findou em uma Ação Popular (BRASIL, Processo $n^{0}$ 002294043.2007.4.02.5101) proposta pelos clubes militares contra a União, na Justiça Federal do Rio de Janeiro, pedindo a anulação da portaria do Ministro da Justiça, que concedeu anistia post-mortem a Lamarca, a promoção ao posto de coronel com proventos de general-de-brigada, a reparação econômica no valor de $\mathrm{R}$ \$ 902.715,97, em favor de sua viúva e a indenização suplementar de $\mathrm{R} \$$ 100 mil, igualmente em caráter indenizatório, a sua viúva e aos filhos. Argumentam esses clubes que, de acordo com o artigo 54 do Decreto, será promovido post mortem, de acordo com o $§ 1^{\circ}$ do art. 30 da Lei $\mathrm{n}^{\circ}$ 5.821, de 1972, o oficial que, ao falecer, satisfazia as condições de acesso e integrava a faixa dos oficiais que concorreriam à promoção pelos critérios de antiguidade ou de merecimento, o que deixaria de fora Lamarca, pois, como esse, segundo os arquivos do Exército, desertou, não faria jus à promoção (BRASIL, Processo de Anistia no 2006.01.55584). O Tribunal Regional Federal da $3^{\text {a }}$ Região, em fins de 2014, confirmou a decisão da Comissão de Anistia e reconheceu o direito à promoção de Lamarca, morto durante a ditadura militar, à patente de coronel, com proventos de general de brigada (duas estrelas). O juízo reconheceu expressamente que Lamarca não foi um desertor, mas que caiu na clandestinidade porque sofria ameaças no quartel, afastando a tese levantada pelos clubes militares.

\section{CONSIDERAÇÕES FINAIS}

Procuramos, com essa análise, deitar olhos sobre o legado autoritário a que os militares anistiados ainda hoje estão submetidos. Os militares anistiados disputam espaço social e ideológico, com uma visão bastante difundida, e defendida entre os militares, de que eles não devem gozar dos mesmos direitos dos demais militares. Essa visão, por certo, diferencia negativamente pessoas que já se encontram em situação deficitária juridicamente.

As práticas discriminatórias do Ministério da Defesa e das Forças Armadas não encontram nenhuma guarida no texto da Constituição, não podendo por isso prosperar. Melo indica que, para um discrímen ser introduzido na ordem jurídica, tem que in concreto ser pertinente com os

\footnotetext{
${ }^{8}$ Esse Decreto regulamenta, para o Exército, a Lei no 5.821 de 1972, que dispõe sobre as promoções dos oficiais da ativa das Forças Armadas, dispondo, entre outras coisas, sobre as promoções por antiguidade e merecimento.
}

Revista de Direito Brasileira | Florianópolis, SC | v. 28 | n. 11 | p.164-182 | Jan./Abr. 2021 
"interesses constitucionalmente protegidos, isto é, deve resultar em diferenciação de tratamento jurídico fundada em razão valiosa - ao lume do texto constitucional - para o bem público" (2004, p. 41); assim, para a Lei 10.559, de 2002, realizar uma discriminação entre militares anistiados e não cassados, deve essa distinção ser compatível com os interesses do sistema constitucional. Isso importa acolher o ensinamento de que, quando a Constituição pretende suprir as diferenças, não pode a legislação majorá-las, não pode o legislador ou seu intérprete, como in casu, agir negativamente quando o texto da Carta Maior impõe uma ação positiva.

Nesse diapasão, urge afirmar que os artigos $8^{\circ}$ e $9^{\circ}$ dos Atos das Disposições Constitucionais Transitórias, em nenhum inciso ou alínea, permitem um tratamento diferenciado; pelo contrário, defendem ações que supram e compensem as perdas do anistiado. Se o Texto Constitucional não possui uma linha que assinta com um tratamento que diferencie o anistiado do não cassado, o legislador infraconstitucional, nem, muito menos, um intérprete qualquer podem fazê-lo. $\mathrm{O}$ tratamento diferenciado dado aos militares anistiados majora a estigmatização de sua identidade, prejudicando-lhes a autoestima; contudo, essa distinção praticada pelo Ministério da Defesa fomenta a luta dos anistiados por seu reconhecimento.

As práticas de diferenciação entre os militares, encetadas pelo Ministério da Defesa, exemplificam como, na sociedade brasileira, segundo Chaú, as leis "sempre foram armas para preservar privilégios e o melhor instrumento para repressão e opressão" (2013, p. 262). Essa sociedade abraçada à justificativa legalista que interpreta a Constituição, violando-a, nega direitos, apresentando argumentos que tratam igualmente quem está em posições distintas, fortalecendo as diferenças; interpretações que estão mais interessadas em assegurar privilégios do que recompor perdas materiais e morais, que se utilizam da lei para silenciar as vozes dos anistiados.

Decisões judiciais que corroborem essas práticas reforçam o entendimento de Chauí ao acentuar que a sociedade brasileira é autoritária, pois sua cidadania efetiva-se por meio de uma figura específica: "o senhor-cidadão, e que conserva a cidadania como privilégio de classe, fazendo-a ser uma concessão regulada e periódica da classe dominante às demais classes sociais, podendo-lhes ser retirada quando os dominantes assim o decidem" (2013, p. 262); e a desnaturalização dessas práticas do Ministério da Defesa favorece a derrocada dessa sociedade autoritária.

\section{REFERÊNCIAS}

AGAMBEN, Giorgio. Homo sacer: o poder soberano e a vida nua. Belo Horizonte: Editora UFMG, 2012.

ALENCAR, Claudiana Nogueira. O mito da representação nos estudos críticos da linguagem. PINTO, J. P. e FABRÌCIO, B. F. (orgs.). Exclusão social e microrresistências: a centralidade das práticas discursivas-identitárias. Goiania: Cânone editorial, 2013.

ALTHUSSER, Louis. A Favor de Marx. ZAHAR Editores, 1979.

AMBOS, Kai. in Justicia de transición: informes de América Latina, Alemania, Italia y España. AMBOS, Kai; MALARINO, Ezequiel e ELSNER, Gisela (orgs). Justicia de transición: informes de América Latina, Alemania, Italia y Españna. Montevideo: Konrad-Adenauer-Stiftung, 2009.

ARENDT, Hannah. Sobre a revolução. São Paulo, Companhia das Letras, 2011.

BARBOSA, Rui. Anistia inversa: caso de Teratologia Jurídica. Rio de Janeiro: Typ. do Jornal do Comércio, 1896. 
BAKHTIN, Mikhail. Estética da criação verbal. São Paulo: WMF Martins Fontes, 2010.

BARKER, C. e GALASINSKI, D. Cultural studies and discourse analysis: a dialogue on language and identity. London: Sage publications, 2005.

BECKER, Howard Saul. Falando da sociedade: ensaios sobre as diferentes maneiras de representar o social. Rio de Janeiro: Jorge Zahar, 2009.

BOBBIO, Norberto. MATTEUCCI, Nicola; PASQUINO, Gianfranco. Dicionário de política. 11. ed. Brasília: EdUNB, 1998.

BONAVIDES, Paulo. Ciência política. São Paulo: Malheiros, 1995.

BOURDIEU, Pierre. ¿Qué significa hablar? Economía de los intercambios linguiísticos. Madrid: Akai, 2008.

BRASIL. Ministério da Justiça - Comissão de Anistia. Certidão de Assentamentos - $4^{\circ}$ Regimento de Infantaria - II EX - 2aOI que instrui a prova do requerimento de anistia. Processo de Anistia n ${ }^{\circ}$ 2006.01.55584. Requerente Maria Pavan Lamarca.

BRASIL. Justiça Federal. Seção Judiciária do Rio de Janeiro. Ação no 004283089.2012.4.02.5101. Autor: Monica Rodrigues Pacheco. Réu: União Federal (Ministério da Marinha). $17^{\mathrm{a}}$ Vara Federal.

BRASIL. Justiça Federal. Seção Judiciária do Rio de Janeiro. Ação no 2009.51.01.023644-3. Autor: Emilene Pinheiro Moraes. Réu: União Federal (Ministério Da Aeronáutica). 07ª Vara Federal.

BRASIL. Justiça Federal. Seção Judiciária do Rio de Janeiro. Ação ordinária no 001926533.2011.4.02.5101. Autor: Rute Geraldo Soares Ferreira e Outros. Réu: União Federal (Ministério Da Marinha). 02 ${ }^{\mathrm{a}}$ Vara Federal.

BRASIL. Justiça Federal. Seção Judiciária do Rio de Janeiro. Ação ordinária no 0041343 02.2010.4.02.5151. Autor: Hélio dos Santos. Réu: Fazenda Nacional. 04º Juizado Especial Federal/RJ.

BRASIL. Justiça Federal. Seção Judiciária do Rio de Janeiro. Ação Popular no 002294043.2007.4.02.5101. Autor: Clube naval e outros. Réu: União Federal e outro. $21^{\mathrm{a}}$ Vara Federal.

BRASIL. Supremo Tribunal Federal. Mandado de Segurança: 20032 DF. Relator: Min. Cordeiro Guerra. Data de Julgamento: 04/06/1975. Tribunal Pleno.

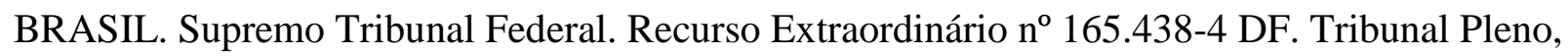
Relator Min. Carlos Veloso. Data de julgamento: 05/05/2006.

BRASIL. Supremo Tribunal Federal. Recurso Extraordinário no 174.161 EDv-ED/DF. Relator Min. Gilmar Mendes, Tribunal Pleno. Data de julgamento: 14/11/2007. 
BRASIL. Superior Tribunal de Justiça. Mandado de Segurança no 11249/DF. Impetrante: Bolívar Marinho Soares de Meirelles. Impetrado: Ministro de Estado da Justiça. Data de julgamento: 24/09/2014

BRASIL. Superior Tribunal de Justiça. Recurso Especial no 1357700/RJ. Rel. Ministro Herman Benjamin. Primeira Seção. Autor: Adeilson José Lopes. Réu: União Federal. Data de julgamento: $12 / 06 / 2013$

CHAUÍ, Marilena. Manifestações ideológicas do autoritarismo brasileiro. Belo Horizonte - São Paulo: Autêntica Editora/Editora Fundação Perseu Abramo, 2013.

CHOULIARAKI, Lilie e FAIRCLOUGH, Norman. Discourse in late modernity. Rethinking critical discourse analysis. Edimburgo: Edinburgh University Press, 1999.

COLARES, Virgínia. Direito Fundamental à Imagem e os Jogos de Linguagem: análise crítica do discurso jurídico. Cadernos da Escola de Direito e Relações Internacionais, Curitiba, 12: 327-350 vol. 1.

DOUZINAS, Costas. O fim dos direitos humanos. São Leopoldo: Unisinos, 2009.

ELIAS, Nobert e SCOTSON, John L. Os estabelecidos e os outsiders: sociologia das relações de poder a partir de uma pequena comunidade. Rio de Janeiro: Zahar, 2000.

FAIRCLOUGH, N. Analysing discourse: textual analysis for social research. London; New York: Routledge, 2003.

FAIRCLOUGH, N. Discurso e mudança social. Trad. I. Magalhães et al. Brasília: Editora Universidade de Brasília [2001], 2008.

FAIRCLOUGH, N. Language and power. Harlow: Pearson Education Limited, 2001.

FERRAZ JR., Tércio. Sampaio. Função social da dogmática jurídica. São Paulo: Ed. Revista dos Tribunais, 1980.

FLORES, Joaquín. Herrera. A reinvenção dos direitos humanos. Florianópolis: Fundação Boiteux, 2009.

FOUCAULT, Michel. Arqueologia do saber. Tradução de Luiz Felipe Baeta Neves. Rio de Janeiro: Forense Universitária, 2010.

GUERRA FILHO, Willis. Santiago. Teoria da ciência jurídica. São Paulo: Saraiva, 2009.

MAGALHÃES, Izabel. Eu e tu: a constituição do sujeito no discurso médico. Brasília: Thesaurus, 2000.

MAGALHÃES, Izabel. Introdução: a análise de discurso crítica. DELTA, São Paulo, v. 21, n. esp., p. 1-9, 2005.

MAGALHÃES, Izabel. Teoria Crítica do Discurso e Texto. Linguagem em (Dis)curso - LemD, Tubarão, v. 4, n.esp, p. 113-131, 2004. 
MAGALHÃES, Izabel. Protagonismo da linguagem: textos como agentes. Revista Brasileira de Linguística Aplicada, 2017. Disponível em: 〈http://dx.doi.org/10.1590/1984-63998201711399>. Acesso em: $26 \mathrm{dez} .2017$.

MAGALHÃES, Izabel; MARTINS, A. R.; RESENDE, V. de M. (2017) Análise de Discurso Crítica: um método de pesquisa qualitativa. Brasília: Editora Universidade de Brasília, 2017.

MELO, Celso Antônio Bandeira de. Conteúdo Jurídico do Princípio da Igualdade. 3. ed. São Paulo: Malheiros, 2004.

MINAYO, Maria Cecília de Sousa. O conceito de representações sociais dentro da sociologia clássica. Textos em representações sociais. Petrópolis: Vozes, 2013.

MORENO, Arley Ramos. Wittgenstein e os valores: do solipsismo à intersubjetividade. Natureza humana. [online]. 2001, vol.3, n.2, pp. 233-288.

MOZDZENSKI, Leonardo Pinheiro. A cartilha jurídica: aspectos sócio-históricos, discursivos e multimodais. 2006. 185 f. Dissertação (mestrado em Letras e Linguística) - Universidade Federal de Pernambuco. Recife, 2006.

PHILIPIS, Susan U. Ideology in the language of judges: how Judges practice law, politics, and Courtroom control. New York: Oxford University Press, 1998.

RAJAGOPALAN, Kanavillil. Linguística e a política de representação. In: Rajagopalan, K. (Org.). Por uma linguística crítica: linguagem, identidade, e a questão ética. São Paulo - SP: Parábola, 2003.

RESENDE, Viviane de Melo. Análise de discurso crítica e etnografia: O Movimento Nacional de Meninos e Meninas de Rua, sua crise e o protagonismo juvenil. 2008. 332 f. Tese (Doutorado em Linguística) - Instituto de Letras, Universidade de Brasília, Brasília, 2008.

RESENDE, Viviane de Melo; RAMALHO, Viviane. Análise de discurso crítica. 2. ed. São Paulo: Contexto, 2013.

RORTY, Richard. A Filosofia e o espelho da natureza. Rio de Janeiro: Reluma-dumará, 1994.

RUBIO, David Sanchez. Derechos humanos, no colonialidad y otras luchas por la dignidad: una mirada parcial y situada. Campo Jurídico, vol. 3, n. 1, p. 181-213, maio de 2015.

WODAK, Ruth. Do que trata a ADC - um resumo de sua história, conceitos importantes e seus desenvolvimentos. Linguagem em (Dis)curso - LemD, Tubarão, v. 4, n.esp, p. 223-243, 2004.

VAN DIJK, Teun A. El análisis crítico del discurso. Anthropos, Barcelona, 186, septiembreoctubre, p. 23-36, 1999.

VAN LEEUWEN, Theo. A representação dos atores sociais. PEDRO, Emília Ribeiro. (org.) Análise crítica do discurso: uma perspectiva sociopolítica e funcional. Lisboa: Caminho, 1997. 